\title{
Treatment of lumbar disc herniation: Evidence-based practice
}

This article was published in the following Dove Press journal:

International Journal of General Medicine

8 July 2010

Number of times this article has been viewed

\section{Andrew J Schoenfeld' \\ Bradley K Weiner ${ }^{2}$}

'Department of Orthopedic Surgery, William Beaumont Army Medical Center, Texas Tech University Health Sciences Center, El Paso, TX, USA;

${ }^{2}$ Weill Cornell Medical College and The Methodist Hospital, Houston, TX, USA
Correspondence: Bradley K Weiner 6550 Fannin Street, Suite 2500, Houston, TX 77030, USA

Tel +l 7I3 44I 3595

Email bkweiner@tmhs.org
Clinical question: What is the best treatment for lumbar disc herniations?

Results: For patients failing six weeks of conservative care, the current literature supports surgical intervention or prolonged conservative management as appropriate treatment options for lumbar radiculopathy in the setting of disc herniation. Surgical intervention may result in more rapid relief of symptoms and restoration of function.

Implementation: While surgery appears to provide more rapid relief, many patients will gradually get better with continued nonoperative management; thus, patient education and active participation in decision-making is vital.

Keywords: lumbar disc, herniation, back pain, spine

Definition: Lumbar disc herniation is a common condition that frequently affects the spine in young and middle-aged patients. ${ }^{1,5,11}$ The lumbar intervertebral disc is a complex structure composed of collagen, proteoglycans, and sparse fibrochondrocytic cells that serve to dissipate forces exerted on the spine. As part of the normal aging process, the disc fibrochondrocytes can undergo senescence, and proteoglycan production diminishes. This leads to a loss of hydration and disc collapse, which increases strain on the fibers of the annulus fibrosus surrounding the disc. Tears and fissures in the annulus can result, facilitating a herniation of disc material, should sufficient forces be placed on the disc. Alternatively, a large biomechanical force placed on a healthy, normal disc may lead to extrusion of disc material in the setting of catastrophic failure of the annular fibers. ${ }^{5}$

Regardless of etiology, herniations represent protrusions of disc material beyond the confines of the annular lining and into the spinal canal. Back pain may occur due to disc protrusions that do not enter the canal or compromise nerve roots. ${ }^{5}$ The more treatable condition of lumbar radiculopathy, however, arises when extruded disc material contacts, or exerts pressure, on the thecal sac or lumbar nerve roots. ${ }^{5,11}$ The pain associated with lumbar radiculopathy occurs due to a combination of nerve root ischemia and inflammation resulting from local pressure and neurochemical inflammatory factors present within the disc material. ${ }^{5,7,9,11}$

Incidence: Lumbar disc herniations exist on a continuum of degenerative spinal processes that include intervertebral disc degeneration and lumbar spondylosis. ${ }^{5}$ Many studies have demonstrated that lumbar herniations, protrusions, and annular tears are present in asymptomatic individuals and, in certain instances, can represent normal aging of the intervertebral disc. The incidence of lumbar disc herniations, albeit 
asymptomatic, within certain populations has been estimated to be greater than $50 \% .{ }^{5}$ The true incidence of symptomatic lumbar disc herniations, however, has not been satisfactorily characterized due to a lack of consensus regarding what constitutes a symptomatic herniation (ie, back pain alone versus radicular pain versus back pain and radicular pain), as well as a lack of ability to quantify a specific at-risk population. Furthermore, the complete natural history of this disorder is inadequately described, although a variety of anecdotal as well as Level IV-V evidence exists, suggesting that $90 \%$ of patients with lumbar disc herniations will resolve their symptoms without substantial medical intervention. ${ }^{5,7}$

Economics: Disc disorders, back pain, and/or radiculopathy are often grouped together in terms of economic considerations, and a discrete estimation of the effect of symptomatic lumbar disc herniation on the economic system, in terms of days lost to work and reduced productivity, is hard to obtain. Nonetheless, back-related conditions are a common cause of disability, and the US health care system spends over \$1 billion annually to redress these disorders. Recently, annual Medicare spending on lumbar discectomy procedures has been estimated to exceed $\$ 300$ million.

Level of evidence: The evidence presented in this article is largely derived from recent prospective, randomized, controlled trials (RCTs) as well as prospective case-control studies. These include the Spine Patient Outcomes Research Trial (SPORT) ${ }^{19}$ as well as the Maine Lumbar Spine Study. ${ }^{2-4}$ Therefore, the evidence presented in this paper can be graded as Level I-II.

Search sources: Sources used in the preparation of this manuscript included PubMed, MedLine, and the Cochrane Library. An advanced search was performed using the PubMed database and key words, including "intervertebral disc herniation", "lumbar disc herniation", and "lumbar disc displacement". The PubMed search revealed 2370 articles that were potential matches. A similar search method on the Cochrane database returned 6153 potential articles, and a like number was obtained with a search using MedLine. Articles with Level I or II evidence were selected for use in the preparation of this article, as well as other publications found to contain pertinent or unique information.

Outcomes: Outcomes considered in the preparation of this manuscript included the relief of radicular pain, resolution of associated motor and sensory deficits, and restoration of preinjury work-related status and level of function.

Consumer summary: Radicular pain in the lower extremities results from the herniation of disc material into the spinal canal and resultant pressure on a nerve root. The constellation of symptoms can include numbness and weakness, but most often consists solely of leg pain that radiates posterolaterally below the knee from nerves L5 and S1 (sciatica); or, less commonly, into the anterior thigh or groin from nerves L2, L3, and L4 (femoralgia). Sensory abnormalities in the genitals, anus, or perineum often coupled with loss of bladder control (cauda equina syndrome), as well as progressive loss of sensation or motor function in the legs, are ominous signs and warrant urgent evaluation and treatment. In situations where leg pain is the primary symptom, conservative management including physical therapy, judicious use of pain medication and epidural steroid injections, as well as surgical intervention (lumbar discectomy) have been shown to be effective. ${ }^{1-9,12-21}$ Most of the literature supports earlier relief of pain-related symptoms, and possibly earlier restoration of function, in patients who undergo surgery. ${ }^{1-5,8,17,18,20,21}$ The four-year as treated analysis of the SPORT trial, documented advantages for surgical intervention over conservative management that persist for up to four years following surgery. ${ }^{21}$ Additionally, if symptoms have already been present for an extended period of time, discectomy may be more likely to relieve symptoms than continued nonoperative management. ${ }^{12}$ While both conservative and surgical options are shown to be efficacious, the ultimate decision regarding initial and definitive management should be made by the patient based on their desires and individualized requirements, following a frank discussion regarding risks and benefits of the various treatments with their surgeon. ${ }^{7}$

\section{The evidence}

Systematic reviews: $1^{1}$

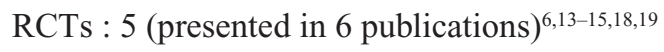

Cohort studies: 4 (presented in 7 publications) ${ }^{2-4,8,17}$

Retrospective series: $1^{16}$

Prior to the mid-1990s there was a paucity of high quality literature supporting the treatment of radicular symptoms resulting from lumbar disc herniation. Since 1996, a number of prospective studies have reported their findings comparing conservative with nonoperative treatments and, in addition, several prospective RCTs have been performed. Many spinal surgeons and medical researchers hoped that well constructed, scientifically rigorous RCTs would definitively answer the 
Table I Prospective, randomized, controlled trials regarding treatment of lumbar disc herniation

\begin{tabular}{|c|c|c|c|c|}
\hline Study & Treatments & Results & $\begin{array}{l}\text { Follow-up } \\
\text { Duration }\end{array}$ & $\begin{array}{l}\text { Percent patient } \\
\text { crossover }\end{array}$ \\
\hline Weber et al ${ }^{18}$ & $\begin{array}{l}\text { Surgery versus nonoperative } \\
\text { management }\end{array}$ & $\begin{array}{l}\text { Significantly better results for surgical } \\
\text { patients after one year }\end{array}$ & Ten years & $35 \%$ C $2 \% \mathrm{~S}$ \\
\hline Buttermann et $\mathrm{al}^{6}$ & $\begin{array}{l}\text { Surgery versus epidural } \\
\text { steroid injection }\end{array}$ & $\begin{array}{l}\text { Better results for surgical patients. } \\
\text { No statistically significant advantage } \\
\text { for surgery }\end{array}$ & $\begin{array}{l}\text { Two to three } \\
\text { years }\end{array}$ & $54 \%$ C 0\% S \\
\hline Osterman et $\mathrm{a}^{13}$ & $\begin{array}{l}\text { Surgery versus conservative } \\
\text { management }\end{array}$ & $\begin{array}{l}\text { No clinically significant differences } \\
\text { between surgery and nonoperative } \\
\text { management }\end{array}$ & Two years & $39 \%$ C 0\% S \\
\hline Weinstein et al ${ }^{19}$ & $\begin{array}{l}\text { Surgery versus NSAIDs, } \\
\text { physical therapy, and } \\
\text { individually tailored } \\
\text { conservative management }\end{array}$ & $\begin{array}{l}\text { No clinically or statistically significant } \\
\text { differences between surgery and } \\
\text { nonoperative treatment }\end{array}$ & Two years & $45 \%$ C $40 \%$ S \\
\hline Peul et al ${ }^{14,15}$ & $\begin{array}{l}\text { Surgery versus pain control } \\
\text { and physical therapy }\end{array}$ & $\begin{array}{l}\text { Early significant benefit for surgical } \\
\text { patients in regard to relief of leg pain. } \\
\text { No difference between groups after } \\
\text { six months }\end{array}$ & $\begin{array}{l}\text { One and two } \\
\text { years }\end{array}$ & $\begin{array}{l}39 \% C^{14} 11 \% S^{14} \\
44 \% C^{15} 11 \% S^{15}\end{array}$ \\
\hline
\end{tabular}

Key: C, Patients randomized to conservative management cross over to surgical group; S, patients randomized to surgery cross over to conservative management group.

question regarding optimal treatment for lumbar disc herniation. However, due to methodologic issues and difficulties with "patient crossover" between treatment groups in these studies, no gold standard treatment has yet been established.

Results from the five RCTs are summarized in Table 1. All of the randomized investigations experienced methodologic difficulty because more than one-third of their randomized patients did not adhere to the treatment that they were assigned to and "crossed over" to the other treatment group. This was most significant in the highly touted SPORT trial, ${ }^{19}$ in which $40 \%$ or more of patients in the surgical and conservative treatment groups declined to have the treatment that they were assigned. This becomes problematic, especially in light of the fact that these randomized investigations were conducted with "intent to treat analysis". Therefore, patients who were assigned to conservative management but decided to undergo surgery were still considered part of the nonoperative group.

Although many of these studies showed some early benefit for surgery, with faster relief of symptoms and return to preinjury functional levels, the findings were not statistically significant. ${ }^{6,14,15,19}$ It is important to note, however, that significant differences between groups become difficult to identify in intent to treat analyses once patient crossover approaches $50 \%{ }^{1}$ Only Weber's study from 1983 was able to show significant advantages for surgery at time points up to one year. ${ }^{18}$

Several publications reporting outcomes for prospective cohorts undergoing discectomy documented satisfactory results, including symptomatic relief and global health benefits for up to two years after surgery (Table 2). The most elaborate prospective study conducted to date remains the report of the Maine Lumbar Spine Study Group, published in a series over the course of 10 years by Atlas et al. ${ }^{2-4}$ Over 500 individuals were included in this investigation, although decisions regarding course of treatment were left to the patients. Evaluations at the $1-^{2}, 5-^{3}$, and 10-year ${ }^{4}$ time points following treatment revealed a continued benefit for surgical intervention, although the two groups approximated each other after a decade. Levels of satisfaction, however, were significantly higher among those patients who had undergone discectomy.

Table 2 Prospective Level II cohort studies regarding treatment of lumbar disc herniation

\begin{tabular}{|c|c|c|}
\hline Investigation & Summary of results & Follow-up duration \\
\hline Spengler et $\mathrm{al}^{17}$ & $77 \%$ of patients treated with discectomy enjoyed a good result & Minimum one year \\
\hline Atlas et $\mathrm{al}^{2-4}$ & $\begin{array}{l}\text { Patients in the surgical group exhibited greater pain relief and higher } \\
\text { satisfaction with treatment up to } 10 \text { years following intervention }\end{array}$ & One, five and 10 years \\
\hline Weinstein et $\mathrm{al}^{20}$ & $\begin{array}{l}\text { Significantly improved outcomes for patients treated surgically at three } \\
\text { months, and one and two years }\end{array}$ & Two years \\
\hline Guilfoyle et $\mathrm{al}^{8}$ & $\begin{array}{l}\text { Significant improvement in SF- } 36 \text { and Roland-Morris scores at an } \\
\text { average of two years of follow-up }\end{array}$ & Median two years \\
\hline Weinstein et $\mathrm{al}^{21}$ & $\begin{array}{l}\text { Significantly improved outcomes for surgical patients in all evaluated } \\
\text { outcome measures at every time point up to four years }\end{array}$ & Four years \\
\hline
\end{tabular}




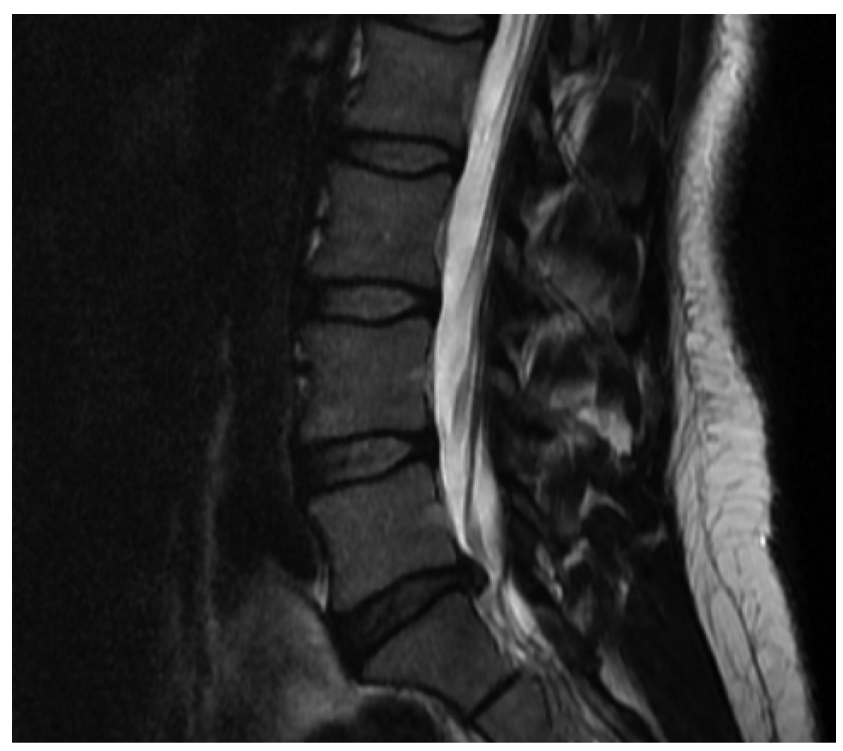

Figure I. Sagittal magnetic resonance image of an L5/SI disc herniation in the setting of degenerative disc disease. The patient was a $4 \mathrm{I}$-year-old woman with a six-week history of right-sided radicular leg pain in an $\mathrm{SI}$ nerve root distribution. The patient failed conservative treatment, including physical therapy and pain management. Her symptoms were successfully relieved with a right-sided L5/SI microdiscectomy.

In 2008, Anderson et al systematically reviewed the results of prospective RCTs investigating treatments for lumbar disc herniation. ${ }^{1}$ These authors found that the degrees of crossover, as well as the performance of intent to treat analyses, in these investigations were severe limitations. Anderson et al felt that, in the absence of intent to treat analysis, the effect of surgery would have been more substantial in the randomized trials. ${ }^{1}$ These authors also maintained that the way in which most RCTs, and SPORT in particular, were conducted did not examine the effects of the surgical and nonoperative treatments under study in a valid manner.
The 1989 study by Saal and Saal is often quoted as evidence for the effectiveness of nonoperative management. ${ }^{16}$ In this retrospective investigation, the authors reported that $90 \%$ of 58 patients treated with a conservative regimen achieved good results or better. An important drawback regarding this series is that, of 347 patients initially identified for enrollment, only 58 were able to be followed to the study's completion. Therefore, while Saal and Saal clearly demonstrated the feasibility of positive outcomes from conservative management, a fact which has been demonstrated in several more recent investigations, the results might represent nothing more than an ideal scenario. Only the most positive outcomes may have been presented in this report, and failures of conservative management in potentially 289 patients were possibly not available to the researchers, or excluded due to the study's inclusion criteria.

\section{Conclusion}

The literature supports both conservative management and surgical intervention as viable options for the treatment of radiculopathy caused by lumbar disc herniation. Methodological drawbacks limit the effect that published RCTs can have on informing clinical practice for this condition. Surgical intervention may result in faster relief of symptoms and earlier return to function, although long-term results appear to be similar regardless of type of management. The ultimate decision regarding type of treatment should be based on a surgeon-patient discussion, in light of proper surgical indications, duration of symptoms, and patient wishes.

\section{The practice}

The patient who presents initially with an acute episode of lumbar radiculopathy can be managed by a primary care practitioner. Primary treatments should include judicious use of pain medication, a short course of rest if indicated, physical therapy, and possible epidural steroid injections. Injections can be ordered, or referral to physiatry or pain management made, prior to considering consultation with a spinal surgeon, unless the patient exhibits certain red flags, such as sensory or motor deficits, progressive neurologic deterioration, or saddle anesthesia with bowel and bladder incontinence. Magnetic resonance imaging (MRI) is indicated to confirm that the patient's symptoms are attributable to appropriate lumbar disc pathology. The following treatment recommendations are not necessarily applicable to those patients who have disc herniations identified on MRI, but present only with back pain.

\section{Potential pitfalls}

Patients with progressive neurologic deficits, saddle anesthesia, and/or bowel or bladder issues should be sent to the emergency room or referred urgently to a spinal surgeon. These patients should not be considered candidates for nonoperative management. Patients with paresthesias or motor weakness in the setting of radicular pain should 
likely be evaluated by a spine care practitioner prior to the determination of a conservative course of treatment. Patients with symptoms present for greater than six months should be referred to a spinal surgeon because nonoperative management may not be indicated in these individuals..$^{5,12}$ Those patients with only back pain, even with MRI evidence of disc herniation, should not be treated using an algorithm for patients with radicular symptoms.

\section{Management}

Initial management should include rest as indicated, physical therapy, and appropriate use of pain medication. In most instances, radicular symptoms will abate or resolve within six weeks. ${ }^{5,7}$ If symptoms persist, consideration can be given to ordering epidural steroid injections. Patients with symptoms that persist beyond six weeks in the setting of demonstrable MRI disc pathology are also candidates for surgical referral.

\section{Assessment}

Assessment by the primary care practitioner consists of taking a history documenting the onset of symptoms and any symptomatic progression. Evaluation should focus on the presence of predominantly back-related symptoms as well as true radicular pain (ie, radiating pain that extends below the knee in the affected extremity). Primary care physicians must also perform a neurologic evaluation to assess for the presence of sensory or motor deficits. Patients with a history of saddle anesthesia must also have a perineal examination and a rectal examination to determine true sensory loss and/or sphincter involvement. Straight leg raise testing and a slump test, as described by Majlesi et al, ${ }^{9}$ are also useful adjuncts. It is important to remember that a true positive straight leg raise test should reproduce the patient's radicular pain, with radiation below the knee in the affected extremity.

\section{Treatment}

Initial treatment can begin with a short course of rest as indicated for the patient with acute lumbar radiculopathy in the setting of a lumbar disc herniation. Pain management may include either a prescription for a moderate nonsteroidal antiinflammatory, such as ibuprofen $800 \mathrm{mg}$ every eight hours as needed, or tramadol $50 \mathrm{mg}$ every 4-6 hours as needed. Patients with more substantial pain can be treated with mild narcotic pain medication, such as hydrocodone-acetaminophen $5 \mathrm{mg} / 500 \mathrm{mg}$ every 4-6 hours on an as-needed basis. Physical therapy referral can be made at the initial office visit, to include mild stretching and pain relief modalities, such as ultrasound, whirlpool, ice and heat pack therapy, electrical stimulation, and/or massage. Those individuals found to have perineal anesthesia, an incompetent rectal sphincter, or significant neurologic deficits by examination should be sent to the emergency room or have an urgent consultation with a surgeon. Those with significant, but stable, sensory or motor deficits may be referred to a spine surgical specialist on an urgent basis. Individuals with a history of more than six months of persistent symptomatology can be referred to a spinal surgeon without consideration for conservative management, because surgical results have been shown to deteriorate after 6-12 months of persistent symptomatology. ${ }^{12}$

Patients who have failed a short course of conservative management (ie, 3-4 weeks) can be considered candidates for epidural steroid injection. Those who have failed six weeks of conservative management and/or derived no relief from steroid injection, may consult with a spine specialist as a routine referral.

\section{Indications for specialist referral}

Urgent specialist referral should be made in the setting of progressive neurologic deficits, saddle anesthesia, or bowel and/or bladder deficits if these issues are acute. Urgent referral to a spinal surgeon can be made if the patient has sensory or motor findings on physical examination but these deficits are stable. Once a patient has failed six weeks of nonoperative treatment, surgical referral is appropriate if symptoms persist and the patient is amenable.

\section{Disclosure}

The authors report no conflicts of interest in this work.

\section{Further reading}

- Anderson PA, McCormick PC, Angevine PD. Randomized controlled trials of the treatment of lumbar disk herniation: 1983-2007. J Am Acad Orthop Surg. 2008;16:566-573.

- Bono CM, Wisneski R, Garfin SR. Lumbar disc herniations. In: Herkowitz HN, Garfin SR, Eismont FJ, Bell GR, Balderston RA, editors. The Spine. 5th ed. Philadelphia, PA: Saunders; 2006.

- McCulloch JA. Focus issue on lumbar disc herniation: Macro- and microdiscectomy. Spine. 1996;21:45S-56S.

- McCulloch JA, Edwards CC II, Riew KD. Lumbar microdiscectomy. In: Bradford DS, Zdeblick TA, editors. Master Techniques in Orthopaedic Surgery: The Spine. Philadelphia, PA: Lippincott Williams \& Wilkins; 2002. 


\section{References}

1. Anderson PA, McCormick PC, Angevine PD. Randomized controlled trials of the treatment of lumbar disk herniation: 1983-2007. J Am Acad Orthop Surg. 2008;16:566-573.

2. Atlas SJ, Deyo RA, Keller RB, et al. The Maine Lumbar Spine Study, Part II. 1-year outcomes of surgical and nonsurgical management of sciatica. Spine. 1996;21:1777-1786.

3. Atlas SJ, Keller RB, Chang Y, Deyo RA, Singer DE. Surgical and nonsurgical management of sciatica secondary to a lumbar disc herniation: Five-year outcomes from the Maine Lumbar Spine Study. Spine. 2001;26:1179-1187.

4. Atlas SJ, Keller RB, Wu YA, Deyo RA, Singer DE. Long-term outcomes of surgical and nonsurgical management of sciatica secondary to a lumbar disc herniation: 10 year results from the Maine Lumbar Spine Study. Spine. 2005;30:927-935.

5. Bono CM, Wisneski R, Garfin SR. Lumbar disc herniations. In: Herkowitz HN, Garfin SR, Eismont FJ, Bell GR, Balderston RA, editors. The Spine. 5th ed. Philadelphia, PA: Saunders; 2006.

6. Buttermann GR. Treatment of lumbar disc herniation: Epidural steroid injection compared with discectomy. J Bone Joint Surg Am. 2004;86:670-679.

7. Carragee E. Surgical treatment of disk disorders. JAMA. 2006;296:2485-2487.

8. Guilfoyle MR, Ganesan D, Seeley H, Laing RJ. Prospective study of outcomes in lumbar discectomy. Br J Neurosurg. 2007;21:389-395.

9. Majlesi J, Togay H, Unalan H, Toprak S. The sensitivity and specificity of the slump and the straight leg raising tests in patients with lumbar disc herniation. J Clin Rheumatol. 2008;14:87-91.

10. McCulloch JA. Focus issue on lumbar disc herniation: Macro- and microdiscectomy. Spine. 1996;21:45S-56S.

11. McCulloch JA, Edwards CC II, Riew KD. Lumbar microdiscectomy. In: Bradford DS, Zdeblick TA, editors. Master Techniques in Orthopaedic Surgery: The Spine. Philadelphia, PA: Lippincott Williams \& Wilkins; 2002.
12. Nygaard OP, Romner B, Trumpy JH. Duration of leg pain as a predictor of outcome after lumbar disc surgery. Acta Neurochir. 1994;128: 53-56.

13. Osterman H, Seitsalo S, Karppinen J, Malmivaara A. Effectiveness of microdiscectomy for lumbar disc herniation: A randomized controlled trial with 2 years of follow-up. Spine. 2006;31:2409-2414.

14. Peul WC, van Houwelingen HC, van den Hout WB, et al; LeidenThe Hague Spine Intervention Prognostic Study Group. Surgery versus prolonged conservative treatment for sciatica. $N$ Engl J Med. 2007;356:2245-2256.

15. Peul WC, van den Hout WB, Brand R, Thomeer RT, Koes BW; LeidenThe Hague Spine Intervention Prognostic Study Group. Prolonged conservative care versus early surgery in patients with sciatica caused by lumbar disc herniation: Two year results of a randomised controlled trial. BMJ. 2008;336:1355-1358.

16. Saal JA, Saal JS. Nonoperative treatment of herniated lumbar intervertebral disc with radiculopathy. An outcome study. Spine. $1989 ; 14: 431-437$

17. Spengler DM, Ouellette EA, Battie M, Zeh J. Elective discectomy for herniation of a lumbar disc. Additional experience with an objective method. J Bone Joint Surg Am. 1990;72:320-327.

18. Weber H. Lumbar disc herniation: A controlled, prospective study with ten years of observation. Spine. 1983;8:131-140.

19. Weinstein JN, Tosteson TD, Lurie JD, et al. Surgical vs nonoperative treatment for lumbar disk herniation: The Spine Patient Outcomes Research Trial (SPORT): A randomized trial. JAMA. 2006;296:2441-2450.

20. Weinstein JN, Lurie JD, Tosteson TD, et al. Surgical vs nonoperative treatment for lumbar disk herniation: The Spine Patient Outcomes Research Trial (SPORT) observational cohort. JAMA. 2006;296: 2451-2459.

21. Weinstein JN, Lurie JD, Tosteson TD, et al. Surgical versus nonoperative treatment for lumbar disc herniation: Four-year results for the Spine Patient Outcomes Research Trial (SPORT). Spine. 2008;33:2789-2800.
International Journal of General Medicine

\section{Publish your work in this journal}

The International Journal of General Medicine is an international, peer-reviewed open-access journal that focuses on general and internal medicine, pathogenesis, epidemiology, diagnosis, monitoring and treatment protocols. The journal is characterized by the rapid reporting of reviews, original research and clinical studies across all disease areas.

\section{Dovepress}

A key focus is the elucidation of disease processes and management protocols resulting in improved outcomes for the patient.The manuscript management system is completely online and includes a very quick and fair peer-review system. Visit http://www.dovepress.com/ testimonials.php to read real quotes from published authors. 